so that at each revolution of the radiometer a record is printed on the strip of paper by dots; close together if the radiometer revolves quickly, farther apart if it goes slower.

The power of the earth on the magnet is too great to ailow the radiometer to start without some initial impetus; there should therefore be an astatic combination inside the bulb, but for a single experiment it may be set going by placing a few coils of insulated copper wire outside the bulb and depressing the battery key for an instant. An electric current is thus passed through the coils of wire, and the interior magnet is immediately deflected from its north-south position; the impetus thus gained enables the light to keep up the rotation.

For the purpose of measuring the amount of force exerted by radiation I constructed a torsion balance capable of indicating the millionth of a grain. A light beam having two square inches of pith at one end is alanced on a fire fibre of glass ${ }^{1}$ stretched horizontally in a tube, one end of the fibre being connected with a torsion handle passing through the tube, and indicating angular movements on a graduated circle. The beam is cemented to the torsion fibre, and the whole is enclosed in glass and connected with the mercury pump by a spiral fube and exhausted as perfectly as possible. A flat oblong piece of soft iron weighing accurately o'or grain is put into the cross tube under the pith surface. This weight can be picked up by a horse-shoe magnet outside the tube and dropped on any part of the pith. A mark is made at the exact centre of the pith surface, and by moving the magnet about it is easy to place the iron weight accurately on this mark. A ray of light from a lamp reflected from a mirror in the centre of the beam to a millimetre scale four feet off shows the slightest movement. When the reflected ray points to zero, a turn of the torsion handle in one direction or the other will raise or depress the pich end of the beam, and thus cause the index ray to travel along the scale to the right or to the left. It a smail weight is placed on one end so as to depress it, and the torsion handle is then turned, the tendency of the glass fibre to untwist itself will ultimately balance the downward pressure of the weight, and will again bring the index ray to zero. It was found that when the weight of the I-Iooth of a grain was placed on the pith surface the torsion handie had to be turned twenty-seven revolutions and $353^{\circ}$, or $10073^{\circ}$ before the beam became horizontal. The downward pressure of the $\mathrm{x}$-rooth of a grain was therefore equivalent to the force of torsion of the glass thread when twisted through $10073^{\circ}$.

I then found out the degree of delicacy of the balance. $x^{\circ}$ of torsion gave a very decided movenient of the index ray, a torsion of $10073^{\circ}$ balancing the 1 -rooth of a grain, while $100074^{\circ}$ overbalanced it. The balance will therefore turn to the $99-100,000,000$ th of a grain.

Weighed in this balance, the mechanical torce of a cardle 12 inches off was found to be 0.000444 grain; of a candle 6 inches off $0^{\circ} 001772$ grain. At half the distance the weight of radiation should be four times, or 0.001776 grain; the difference between theory and experiment being only four millionths of a grain is a sufficient proof that the indications of this instrument follow rigidly the law of inverse squares. An examination of the differences between the separate observations and the mean shows that my estimate of the sensitiveness of this balance is not excessive, and that in practice it will safely indicate the millionth of a grain.

I performed an experiment at the meeting of the Royal Society on March 30 last to demonstrate the movement of the glass case of the radiometer. I made use of a large radiometer in a 4-inch bulb with ten arms, eight of

I The torsion of fibre must be selected with great care. Ten threads were drawn out before the blowpipe and suspended from a horizontal beam. Weights were then gradually hung on to the lower ends. Only two were found strang enough The one selected stood $45^{\circ}$ grains without breaking, its diamster being less than oor incli. which were brass, and the other two a long watch-spring magnet. The discs were of pith blackened on one side.

The instrument was floated in a vessel of water, four candles being placed round it to set the arms in rotation. A mark was put on the glass envelope to enable a slight movement to be seen.

A powerful magnet was now brought near the moving: arms, which immediately stopped, and at the same time the glass envelope commenced to revolve in the opposite direction to that in which the arms had been revolving. The movement kept up as lono as the candles were burning, and the speed was one revolution in two minutes. On the magnet being removed the arms obeyed the force of radiation from the candles and revolved rapidly, whilst the glass envelope quickly came to rest. The candles were then blown out, and as soon as the whole instrument had come to rest, a bar-magnet was moved alternately from one side to the other of the radiometer, so as to cause the vanes to rotate as if they had been under the influence of a candle. The glass envelope moved about one revolution in three minutes in the same direction as the arms, and on reversing the direction of movement of arms, the glass envelope changed direction also. This I consider is proof that the internal friction, either of the steel point on the glass socket or the vanes against the residual air, or of both these causes combined, is considerable. Movino the vanes round by the exterior magnet carries the whole envelope round in opposition to the friction of the water against the glass.

In another communication I propose to give the results of my experiments on the influence of the residual gas on the movement of the radiometer, and also refer to other results which I have recently obtained.

William CROOKeS

\section{ON A NEW ASTRONOMICAL CLOCK}

7 HE object of this communication was to explain to members of the Association and give them ari opportunity of sceing in my house in the University a clock which had been described in a communication to the Royal Society, in 1859, entitled "On a New Astronomical Clock and a. Pendulum Governor for Uniform Motion." The following description is taken from the Proceedings of the Royal Society for I869, except a few alterations and additions, and except the drawings, which have not been hitherto published :---

It seems strange that the dead-beat escapement should still hold its place in the astronomical clock, when its geometrical transformation, the cylinder escapement of the same inventor, Graham, only survives in Geneva watches of the cheaper class. For better portable timekeepers it has been altered, through the vicious rack-andpinion movement, into the superlatively good detached lever. If it is possible to make astronomical clocks go better than at present by merely giving them a better escapement, it is quite certain that one on the same principle as the detached lever, or as Earnshaw's shipchronometer escapement, would improve their timekeeping.

But the irregularities hitherto tolerated in astronomical clocks may be due more to the faultiness of the steel and mercury compensation pendulum, with its loosely attached glass jar, and of the mode in which it is hung, and to instability of the supporting clock-case or framework, than to imperfection of the escapement and the greatness of the arc of vibration which it requires; therefore it would be wrong to expect confidently much improvement in the time-keeping merely from improvement of the escapement. I have therefore endeavoured to improve both the compensation for change $x$ " On a New Form of Astronomical Clock with Free Pendulum and Independently Governed Uniform Motion for Escapement Wheel." By Prof. Sir William Thomson, F.R.S. (Communicated to Section A of the British Association, Thursday, September $7,1876$. 
of temperature in the pendulum, and the mode of its support, in a clock which I have recently made with an escapement on a new principle, in which the simplicity of the dead-beat escapement of Graham is retained, while its arcat defect, the stopping of the whole train of wheels by pressure of a tooth upon a surface moving with the pendulum, is remedied.

Imagine the escapement-wheel of a common dead-beat clock to be mounted on a collar fitting easily upon a shaft, instead of being rigidly attached to it. Let friction be properly applied between the shaft and the collar, so that the wheel shall be carried round by the shaft unless resisted by a force exceeding some small definite amount ; and let a governor giving uniform motion be applied to the train of wheel-work connected with this shaft, and so adjusted that, when the escapement-wheel is unresisted, it will move faster by a small. percentage than it must move to keep time properly. Now let the escapement wheel, thus mounted and carried round, act upon the escapement, just as it does in the ordinary clock. It will keep the pendulum vibrating, and will,
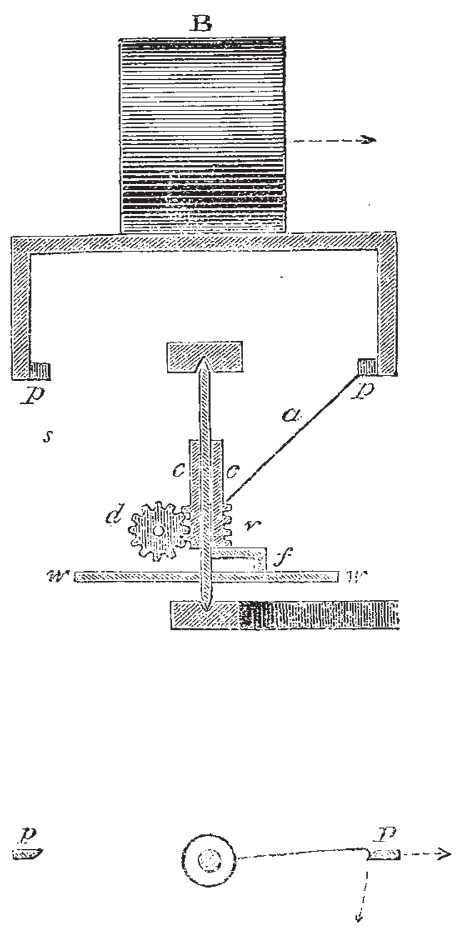

just as in the ordinary clock, be held back every time it touches the escapement during the interval required to set it right again from having gone too fast during the preceding interval of motion. But in the ordinary clock the interval of rest is considerable, generally greater than the interval of motion. In the new clock it is equal to a small fraction of the interval of motion : $\frac{1}{30} \overline{0}$ in the clock as now working, but to be reduced probably to something much smaller yet. The simplest appliance to count the turns of this escapement-wheel (a worm, for instance, working upon a wheel with thirty teeth, carrying a hand round, which will correspond to the seconds' hand of the clock) completes the instrument; for minute and hour-hands are a superfluity in an astronomical clock.

In various trials which I have made since the year r865, when this plan of escapement first occurred to me, I have used several different forms, all answering to the preceding description, although differing widely in their geometrical and mechanical characters. In all of them the escapement-wheel is reduced to a single tooth or arm, to diminish as much as possible the moment of inertia of the mass stopped by the pendulum. This arm revolves in the period of the pendulum (two seconds for a one second's pendulum), or in some odd multiple of it. 'Thus the pendulum may execute one or more complete periods of vibration without being touched by the escipenent. In all my trials the pallets have been attached to the bottom of the pendulum, projecting below it, in order that satisfactory action with a very small arc of vibration (not more on each side than $\frac{1}{100}$ of the radius, or I centimetre for the seconds' pendulum) may be secured.

In the clock in my house the seconds' pendulum of the fine movement, vibrates with great constancy through half a millimetre, that is to say, through an arc of $-\frac{7}{0} 0$ of the radian, on each side of the vertical. This, I believe, is the smallest range that has hitherto been realised in any seconds' pendulum of an astronomical or other clock.

In the drawing $s$ represents the vertical escapement shaft, round which is fitted loosely the collar $c$, carrying the worm $v$. The small wheel, $d$, is worked by $v$, and carries round the seconds' hand of the clock. a represents a piece of fine steel wire, being the single arm to which the teeth of the escapement-wheel are reduced in the clock described in this paper; $p p$ the pallets attached to bars projecting downwards from the bob, $\mathbb{B}$, of the pendulum; $f$, a foot bearing the weight of the collar-worm and escapement tooth. The bar connecting $f$ with the collar is of such a length as to give a proper moment to the frictional force by which the collar is carried round. The shaft $s$ carries a whel, represented in section by $w w$, which is driven by a train of wheelwork (not shown in the drawing) from the governor. This wheel is made to go 1 per cent. faster than once round in two seconds, while the pendulurn prevents the collar from going round more than once in two seconds.

My trials were rendered practically abortive from 1865 until a few months ago by the difficulty of obtaining a satisfactory governor for the uniform motion of the escapement-shaft; this difficuity is quite overcome in the pendulum governor, which I now proceed to describe.

Imagine a pendulum with single-tooth escapenent mounted on a collar loose on the escapement shaft just as described above-the shaft being vertical in this case also. A square-threaded screw is cut on the upper quarter of the length of the shaft, this being the part of it on which the escapement-collar works; and a pin fixed to the collar projects inwards to the furrow of the screw, so that, if the collar is turned relatively to the shaft, it will be carricd along, as the nut of a screw, but with less friction than an ordinary nut. Below the screw and long nut-collar, threequarters of thelength of the escapement-shaft is surrounded by a tube which, by wheel-work, is carried round about 5 per cent. faster than the central shaft. This outer shaft, by means of friction produced by the pressure of proper springs, carries the nut collar round along with it, except when the escapement-tooth is stopped by either of the pallets attached to the pend11lum. A stiff cross-piece 'like the head of a $T$ ), projecting each way from the top of the tubular shaft, carries, hanging down from it, the governing masses of a centrifugal friction governor. These masses are drawn towards the axis by springs, the inner ends of whicts are acted on by the nut collar, so that the lower or the higher the latter is in its range, the springs pull the masses inwards with less or more force. A fixed metal ring coaxial with the main shaft holds the governing masses in when their centrifugal forces exceed the forces of the springs, and resists the motion by forces of friction increasing approximately in simple proportion to the excess of the speed above that which just balances the forces of the springs. As long as the escapement-tooth is unresisted, the nut collar is carried round with the quicker motion of the outer tubular shaft, and so it screws $u p$ wards, increasing the force of the springs. Once every semiperiod of the pendulum it is held back by either 
pallet, and the nut-collar screws down as much as it rose during the preceding interval of freedom when the action is regular; and the central or main escapement-shaft turns in the same period as the tooth, being the period of the pendulum. If through increase or dimizution of the driving-power, or diminution or increase of the coefficient of friction between the governing masses and the ring on which they press, the shaft tends to tun faster or slower, the nut collar works its way down or up the screw, until the governor is again regulated, and rives the same speed in the altered circumstances. It is casy to arrange that a large amount of regulating power shall be implied in a single tum of the nut collar relatively to the central shaft, and yet that the periodic application and removal of about $\frac{x}{10}$ of this amount in the half period of the pendulum shall cause but a very small periodic variation in the speed. The latter important condition is secured by the great moment of inertia of the governing masses themselves round the main shaft. My communication to the Royal Society ended as follows:-

"I hope after a few months' trial, to be able to present a satisfactory report of the performance of the clock now completed according to the principles explained above. As many of the details of execution may become mocified after practical trial, it is unnecessary that I should describe them minutely at present. Its general appearance, and the arrangement of its characteristic parts, may be understood from the photograph now laid before the Society."

I am sorry to say that the hope here expressed has not hither to been realised. Year after year passed producing only more or less of radical reform in various mechanical details of the governor and of the fine movement, until about six months ago, when, for the first time, I had all except the pendulums in approximately satisfactory condition. By that time $I$ had discovered that my choice of zinc and platinum for the temperature compensation, and lead for the weicht of the pendulums. was a mistake. I jad fallen into it about ten years ago through being in formed that in Russia the gridiron pendulum had been reverted to because of the difficulty of getting equality of temperature throughout the length of the pendulum; and without stooping to perceive that the right way to deal with this difficulty was to face if and ake means of securing practical equality of temperature throughout the length of the pendulun (which it is obvious may be cone by simple enough appliances), I devised a pendulam in which the compensation is produced by a stiff tube of zinc and a platinum wire placed nearly parailel each to the other throughout the length of the pendulum. The two pendulums of the clock shown to the British Association were constructed on this plan. Now it is clear that the materials chosen for compensation should, of all those not otherwise objectionable, be those of greatest and of least expansibility. Therefore, certainly, glass or platinum ought to be one of the materials, and the steel of the ordinary astronomical mercury pendulum is a mistake. Mercury ought to be the other (its cubic expansion being six times the linear expansion of zinc) unless the capillary uncertainty of the mercury surface lead to irregular changes in the rate of the pendulum. The weight of the pendulum ought to be of material of the greatest specific gravity attainable; at all events unless the whole is to be mounted in an air-tight case ; because one of the chief errors of the best existing pendulums is that depending on the variations of barometric pressure. The expense of platinum puts it out of the question for the weight of the pendulum, even although the use of mercury for the temperature compensation did not also give mercury for the weight. Thus even though as good compensation could be got by zinc and platinum as by any other means, mercury ought on account of its superior specific gravity (nearly three times that of lead) to be preferred to lead for the weight of the pendulum.
I have accordingly now made several pendulums (for tide-gauges) with no other material in the moving part than glass and mercury, and with rounded knife edges of agate for the fixed support; and I an on the point of making four more for two new clocks which I am having made on the plan. which forms the subject of this communication. I have had no opportunity hitherto of testing the performance of any of these pendulums, but their action seems very promising of good results, and the only untoward circumstance which has hitherto appeared in connection with them has been breakages of the glass in two atcempts to have one carried safely to Genoa for a tidegauge made by Mr. White, to an order for the Italian Government.

As to the accuracy of my new clock, it is enough to look at the pendulum vibrating with perfect steadiness, from month to month, through a range of half a centimetre on each side of its middle position, with its pallets only touched during $\frac{7}{4}$ of the time by the escapement-tooth, to feel certain that, if the best ordinary astronomical clock owes any of its irregularities to variations of range of its pendulum or to impulses and friction of its escapementwheel, the new clock must, when tried with an equally good pendulum, prove more regular. I hope soon to have it tried with a better pendulum than that of any astronomical clock hitherto made, and if it then shows irregularivies amounting to $\frac{1}{10}$ of those of the best astronomical clocks, the next step must be to inclose it in an air-tight case kept at constant temperature, day and night, summer and winter.

\section{ON THE TROPICAL FORESTS OF HAMPSHIRE:}

FNGLAND at the present time has a climate far from tropical, but at the time to which this Iecture refers the paim and spice plantis flourished here; and hence tie climate then may rightly be spoken of as actually tropical.

The dita on which this inference is based are the fosill leaves which are found in the clays of the south of Hampshire. Out of the many thousands of such leaves obtained by me during summer holidays for many years past, some selected specimens were exhibited in a cabinet in the Loan Coliection of Scientific Instruments. Other collections of leaves from this spot and from Alum Bay have been mad; and may be seen in the British Museum. It is the district immediately along the line east and west of Bournemouth which has been specially exanined, and it is in the lower Bagshot beds, which are, comparatively speaking, amongst the youngest of the geological scale, that the leaves referred to have been found.

These Basshot beds need not detain us; but as I have referred to them as amongst the youngest in the geological scale, I may mention that above them we have the Bracklesham beds, full of marine forms; the Barton beds, also full of marine forms, but telling a tale of a different sea; the Headon, Bembridge, and Hempstead series, with many repetitions of marine and fresh-water conditions, indicating long lapses of time. There is, too, the whole Miocene period, of which we have no trace in this district, but which we believe from continental evidence was of vast duration. Then, too, there followed periods of immense length, during which England underwent its latest glacial epoch; after that, the time during which the gravels were formed. While, thcrefore, we speak of these beds as almost the youngest of our series, they belong to periods of an incalculably remote past.

It is from the cliffs principally, and from the deep cuttings of the recently constructed railway from Bournemouth to Parkstone, that our knowledge is mainly derived. There are, in addition, the diggings carried on

I Lecture in connection with the Loan Collection of Scientific Apparatus, given at the South Kensington Museum, December $2 x 876$, by J. Starkie Gardner, F.G.S. 